\title{
Participation and Achievement in the Summer Paralympic Games: The Influence of Income, Sex, and Assistive Technology
}

\author{
Giulia Oggero $^{1, *}$, Louise Puli ${ }^{1}\left[\right.$, Emma Maria Smith ${ }^{2}$ and Chapal Khasnabis ${ }^{1, *}$ \\ 1 Access to Assistive Technology Team, World Health Organization, 1211 Geneva, Switzerland; puli1@who.int \\ 2 Assisting Living and Learning Institute, Maynooth University, W23 F2K8 Kildare, Ireland; \\ Emma.Smith@mu.ie \\ * Correspondence: oggerog@who.int (G.O.); khasnabisc@who.int (C.K.)
}

\section{check for} updates

Citation: Oggero, G.; Puli, L.; Smith, E.M.; Khasnabis, C. Participation and Achievement in the Summer

Paralympic Games: The Influence of Income, Sex, and Assistive Technology. Sustainability 2021, 13, 11758. https://doi.org/10.3390/ su132111758

Academic Editor: Giuseppe Battaglia

Received: 10 August 2021

Accepted: 13 October 2021

Published: 25 October 2021

Publisher's Note: MDPI stays neutral with regard to jurisdictional claims in published maps and institutional affiliations.

Copyright: @World Health Organization [2021]. All rights reserved. The World Health Organization has granted the Publisher permission for the reproduction of this article.

\begin{abstract}
Global participation at the Paralympic Games has been steadily growing in the past 60 years. However, inequities in relation to geographic representation of Paralympians, sex representation, access to assistive technology, and medal success remain. The objectives of this research are to describe and compare trends in Paralympians' participation and achievements in the Summer Paralympic Games by income level and sex, including in events requiring assistive products (wheelchairs, hand cycles/trikes, and prostheses). A retrospective secondary analysis of publicly available data was conducted. Participation, sex, and medal tally data were extracted from data available on the International Paralympic Committee website and archives. Data regarding income and population were collected from publicly available data available from the World Bank website. Participation in the Summer Paralympic Games differs significantly by income level $(p=0.000)$ with high- income countries sending, on average, more Paralympians than low- and middle-income countries. There is a significant difference between male and female participation $(p=0.00)$, with approximately $29 \%$ of all Paralympians being female. High-income countries demonstrate significantly higher achievement than low- and middle-income countries $(p=0.000)$, including in events requiring assistive products $(p=0.007)$. Despite growth in overall participation, low- and middle-income countries remain severely underrepresented in both participation and achievement at the Paralympic Games, especially in the events that require high quality assistive products to succeed. More equitable participation and achievement in the Paralympics may be supported by addressing the barriers for females, for people from low- and low-middle income countries, and for those without access to high quality assistive products required.
\end{abstract}

Keywords: assistive technology; disability; Paralympic Games

\section{Introduction}

The Paralympic Games is a quadrennial, global, multi-sports competition for persons with disabilities. The right to participate in sport, recreation, and play is enshrined as a standalone provision in the United Nations' Convention on the Rights of Persons with Disabilities [1], the Kazan Action Plan, and also features in other conventions including the Convention on the Rights of the Child and the Convention on the Elimination of All Forms of Discrimination against Women [2,3]. While the primary focus of the Paralympic Movement has been on participation in sport, in recent years, the Paralympic Games has proven to be an invaluable driver for advancing disability rights, equality of opportunities, integration, and inclusion [4].

Growing global interest and engagement in the Paralympics is evidenced by the increase in the number of participating countries and Paralympians worldwide [4]. Previous studies suggest however, that concerning inequalities in participation and achievement remain. The Paralympic Games have been found to mirror the Olympic Games, with females participating less than males. This disparity is near impossible to avoid given that 
certain Paralympic events do not offer a female category for participation, and others only offer mixed-sex participation $[5,6]$.

Considering country income level, Paralympians from low- and low-middle-income countries may be less likely to participate and achieve a medal at the Paralympics [7]. Research has previously highlighted that low- and middle- income countries tend to send smaller teams compared to high-income countries and are less represented in global medal tables [8,9]. Previous studies in similar international competition also suggest lowand middle-income countries are less likely to participate in events requiring expensive equipment and technology [7].

Given that many Paralympic events require the use of high quality assistive products, such as prosthetic blades, sport-wheelchairs, or racing handcycles/trikes, lack of access to these has been linked to the gap in achievement and under-representation of low- and middle-income countries in Paralympic Games [9]. Access to high quality, affordable assistive products for sports, including the availability of maintenance facilities in the athlete's home country, is inextricably linked to opportunities to access training, sports facilities, and to succeed in global competitive events $[10,11]$. The Convention on the Rights of Persons with Disabilities recognizes access to assistive products as a fundamental human right, and their essential role in promoting participation and inclusion within recreational, sport, and leisure activities (Article 20 and 30). Despite the Convention being ratified by 182 countries as of June 2021, access to assistive products remains largely limited.

The World Health Organization (WHO) estimates that globally, only $10 \%$ of people have access to the assistive products they need [12]. For example, in certain countries, only $5 \%$ to $10 \%$ of those in need have access to a wheelchair. In some less-resourced settings, the production of hearing aids only meets $3 \%$ of the need [12]. Common barriers include lack of awareness, policies, and regulation; lack of data on need and unmet need for assistive products; limited innovation and involvement of users in the design process; unaffordability, unavailability, and poor quality of assistive products; shortage of adequately trained health personnel; and fragmented and inaccessible facilities and services [13-15]. Access to assistive technology, their impact on users, the challenges in access across different socio-economic contexts, and effective solutions to improve access are still widely under-researched areas. Access to high quality assistive products and its relationship to participation and achievement in competitive sports is even less well studied.

Despite the lack of evidence in the wider literature about the availability of assistive technology for Paralympic sports, logical inferences can be made. Given that many countries have limited national service delivery for basic assistive products for day-to-day life, they may be even less likely to have the ability to support provision of the advanced assistive products and equipment required for participation in the Paralympics [16,17]. In the majority of countries, the provision of specialized assistive products and technology for competitive events is not mainstreamed within national policies, and often excluded from reimbursement and financial schemes [18]. In addition, in many contexts, including highincome countries, persons with disabilities face additional challenges in accessing training and sport facilities. The lack of professional preparation among physical activity personnel and trainers coupled with environmental barriers represent some of the main challenges for persons with disabilities to shift from participation in recreational and amateur activities to competitive sports [19].

While previous studies have highlighted inequalities in participation and success for a single or a few Paralympic events [8], research and trends describing global historic participation of countries from different income groups in Paralympics events, sex representation and medal success are currently not available. In addition, it is unknown how factors such as countries' income level and sex have affected performance in Paralympics sports that require the use of high-quality assistive products, such as wheelchairs and prosthetics. Therefore, this study aims to explore the relationships between income level, sex (as defined by the International Paralympic Committee), participation, and achievement in the 
Summer Paralympic Games to inform future reforms, promoting fairness and increasing equality of access to high-quality assistive products.

The objective of this research is to describe the relationships between income, sex representation, participation, and achievements at the Summer Paralympics Games in relation to income, with an additional focus on selected events requiring assistive products. The specific objectives of this research are to describe and compare:

1. The number of Paralympians participating in the Summer Paralympic Games by income level and sex;

2. The number of Paralympians participating in selected events requiring assistive products (wheelchairs, hand cycles, and prostheses) by income level; and

3. Medal achievement by income level in all events and events requiring assistive products.

\section{Materials and Methods}

\subsection{Research Design}

To describe and compare difference in Paralympic participation and achievement by income, sex, and use of assistive products, we conducted a retrospective secondary analysis of publicly available data from the International Paralympic Committee. To collect specific data regarding events requiring assistive products, we identified a cross section of events requiring the use of a wheelchair, handcycle, or prosthesis for participation. This included six key summer Paralympic events: wheelchair fencing, wheelchair basketball, wheelchair tennis, wheelchair rugby, athletics (100 m, $200 \mathrm{~m}$, and $400 \mathrm{~m}$ running with prothesis), long jump with prosthesis, and cycling (handcycles). Although assistive products may be used for other events, these may not specifically require the use of assistive products. We were unable to extract specific use of assistive products for additional events. Data for events requiring assistive products in Summer Paralympic Games held prior to 1996 were excluded due to limitations in event-specific data prior to 1996.

\subsection{Inclusion and Exclusion Criteria}

We included countries which participated in at least one Paralympic Games between 1960 and 2016 in the analysis (Appendix A lists the countries included in the analysis). Countries were excluded if they participated in past Summer Paralympics but do not exist anymore (i.e., Rhodesia, East and West Germany, and Yugoslavia). For countries with a name change over the years considered (1960-2016), the latest official name was used.

\subsection{Data Extraction and Synthesis}

Participation, sex, and medal tally data were extracted from data available on the International Paralympic Committee website, Athletics World Committee, and Archive page in the period from 20 January to 15 March 2021 by two authors (G.O., L.P.). Data regarding income (income level, GDP) and countries' population size were extracted for each country by year from publicly available data available from the World Bank website by another author ((E.S.). Sex of participants (male, female) was based on the classification used by the International Paralympic Committee when reporting medal tally and participation. We could not use gender classification (man, woman) in this instance as identity, psychosocial, or cultural factors were not recorded.

Data were extracted for each country participating in the Summer Paralympic Games included:

1. Number of Paralympic Games attended;

2. Number of Paralympians sent each year between 1960-2016, disaggregated by sex;

3. Number of medals won, disaggregated by type of medal (gold, silver, and bronze); and

4. Medal results for events requiring the use of assistive products (wheelchairs, prostheses, and hand cycles). 
Both team and individual events were included in the study. The medals won by a team were counted as one medal. Data were checked independently for accuracy and completeness by three authors.

\subsection{Data Analysis}

Data analyses were completed using MS Excel for descriptive statistics and data visualization, and SPSS for statistical analyses. Descriptive statistics (counts, proportions, means) were used to illustrate trends in Paralympians' participation, sex representation, and achievements. Countries were grouped based on their income (low-income, lowermiddle income, upper-middle income, and high-income) according to the World Bank classification. Where countries changed income levels, the mode level of all years for that country was used. In cases where the mode value was unclear (i.e., equal number of years at each of two levels), the higher level was used. To compare participation and achievement data for across income levels and sex, analysis of variance (ANOVA), controlling for population, was used to determine if differences in means were significant between groups. Significance is reported using $p$-values where $p \leq 0.05$ is considered significant, suggesting the difference between groups is not due to chance. In cases where groups did differ significantly, Tukey's post hoc analysis was used to determine whether differences between individual groups were significant.

Overall achievement was calculated as a mean number of athletes who won a medal (\#medals/\#athletes $\times 100$ ) for each country per year. For events requiring assistive products, due to limitations in the data, achievement was calculated as a proportion of medals won per event participated in by each country per year (\#medals/\#events $\times 100$ ). We were unable to extract number of events participated in in the overall data or the number of athletes participating in events requiring assistive products; therefore, we were not able to calculate comparable metrics between overall achievement and achievement in events requiring assistive products.

\subsection{Ethical Approval}

As this is a secondary analysis of publicly available data, there is no requirement for research ethics board approval for this research.

\section{Results}

Results are reported in two sections. The first reports general trends in participation, sex representation, and medal achievements in relation to income level across all Paralympic events. The second reports participation and achievement for events requiring assistive products.

\subsection{Participation and Achievement in Summer Paralympic Games (1960-2016)}

A total of 179 countries were included in the analysis, represented by a total of 35,598 Paralympians. Participation in the Summer Paralympic Games differs significantly by income level ( $p=0.000)$ with high-income countries sending more Paralympians than low-and middle-income income countries. Figure 1 shows the number of Paralympians participating from countries from each of the four income levels. Section 3.1.

While the overall number of Paralympians differs significantly by income level, the proportion of female athletes does not. There is a significant difference between male and female participation ( $p=0.000$ ), with approximately $29 \%$ of all Paralympians being female. As shown in Table 1 , there is very little variation across income levels $(p=0.869)$. Figure 2 shows the number of male and female Paralympians by year. Those countries with the high proportions of female participation typically have a low number of participating Paralympians. Countries with greater than $50 \%$ female participation $(\mathrm{n}=$ number of Paralympians overall, $\mathrm{f}=$ number female) are Bermuda $(\mathrm{n}=10, \mathrm{f}=8)$, Estonia $(\mathrm{n}=44, \mathrm{f}=24$, Faroe Islands $(n=17, f=13)$, Lesotho $(n=8, f=5)$, Malawi $(n=1, f=1)$, Mauritania $(n=5$, 
$f=3)$, Mozambique $(n=3, f=2)$, Singapore $(n=52, f=28)$, Solomon Islands $(n=1, f=1)$, and Viet Nam $(\mathrm{n}=36, \mathrm{f}=19)$.

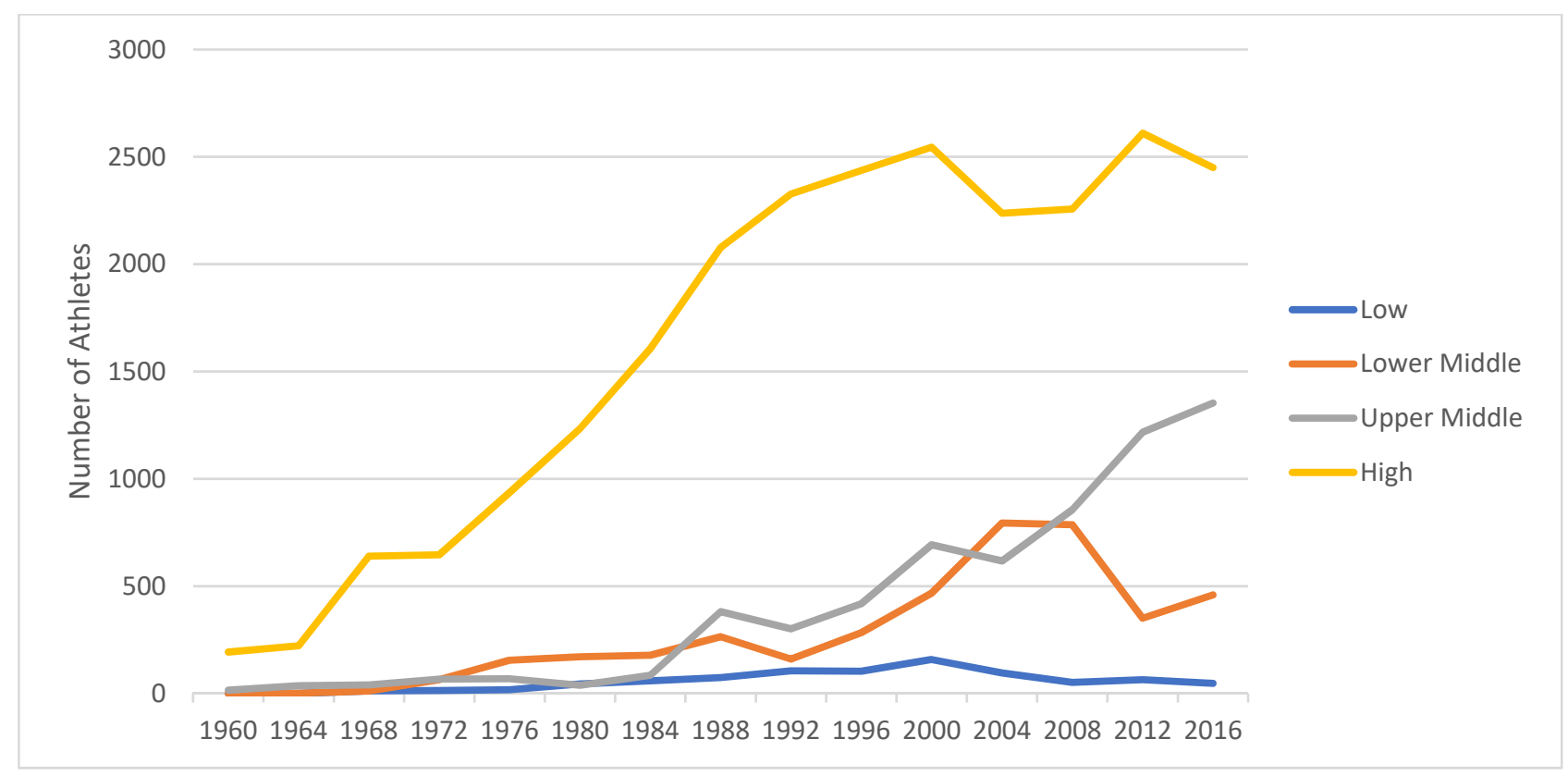

Figure 1. Number of Paralympians per year from 1960 to 2016 by income level.

Table 1. Participation and achievement in Summer Paralympic Games from 1960-2016 by income level.

\begin{tabular}{|c|c|c|c|c|c|}
\hline Participation and Achievement & Low & Lower Middle & Upper Middle & High & All Countries \\
\hline $\begin{array}{c}\text { Paralympians representing } \\
\text { countries }(n)\end{array}$ & 672 & 4625 & 5528 & 24,773 & 35,598 \\
\hline Male (n) & 483 & 3237 & 3871 & 17,583 & 25,174 \\
\hline Female (n) & 189 & 1388 & 1657 & 7190 & 10,424 \\
\hline Proportion female, Overall (\%) & 28.13 & 30.01 & 29.97 & 29.02 & 29.28 \\
\hline $\begin{array}{l}\text { Achievement, mean per country } \\
\qquad(\%, 95 \% \mathrm{CI})^{1}\end{array}$ & 5.44 & 19.97 & $27.72 *$ & $36.99 *$ & 22.63 \\
\hline $\begin{array}{l}\text { Proportion of countries with no } \\
\text { medal achievement (\%) }\end{array}$ & 72.73 & 30.77 & 25.00 & 17.65 & 36.31 \\
\hline
\end{tabular}

${ }^{1}$ Achievement represents mean proportion of athletes who won a medal (number of athletes divided by number of medals); ${ }^{*}$ Indicates the value is significantly different from low income countries in the analysis at $p \leq 0.05$.

Between 1960-2016, a total of 19.431 medals (including gold, silver, and bronze) were won across all countries. High-income and upper middle-income countries have significantly higher rates of achievement $(p \leq 0.05)$ than low-income countries (see Table 1 ). Table 1 also lists the proportion of countries with no medal achievement over the 15 Paralympic Games. The proportion of countries in each level that have not won a medal is inversely proportional to income level. Furthermore, at higher income levels, there is more consistent distribution of medal achievement. For example, in low-income countries, only four countries dominated overall achievement, representing outliers (greater than 2 standard deviations above the mean). These countries were Nigeria, Kenya, Mozambique, and Myanmar, which had achievement rates of $53.44 \%, 34.04 \%, 33.33 \%$, and $31.82 \%$, respectively; the majority of countries $(72.73 \%)$ in this level have never been awarded a medal. In lower-middle income countries, only two countries were outliers of the mean achievement rate. These countries were Jamaica $(72.37 \%)$ and Uzbekistan $(71.11 \%)$. Approximately one third $(16,30.77 \%)$ of countries in this level have never been awarded a medal. In upper-middle income countries, there was an outlier (Poland, $89.45 \%$ ), while one quarter $(8,25 \%)$ of countries have never been awarded a medal. In high-income countries, 
there were no outliers, and less than one fifth $(17.65 \%)$ of countries in this level have never been awarded a medal. However, over the entire duration of the Paralympic Games, those high-income countries with no achievement have only contributed a total of $0.22 \%$ of the total number of athletes from within that income level.

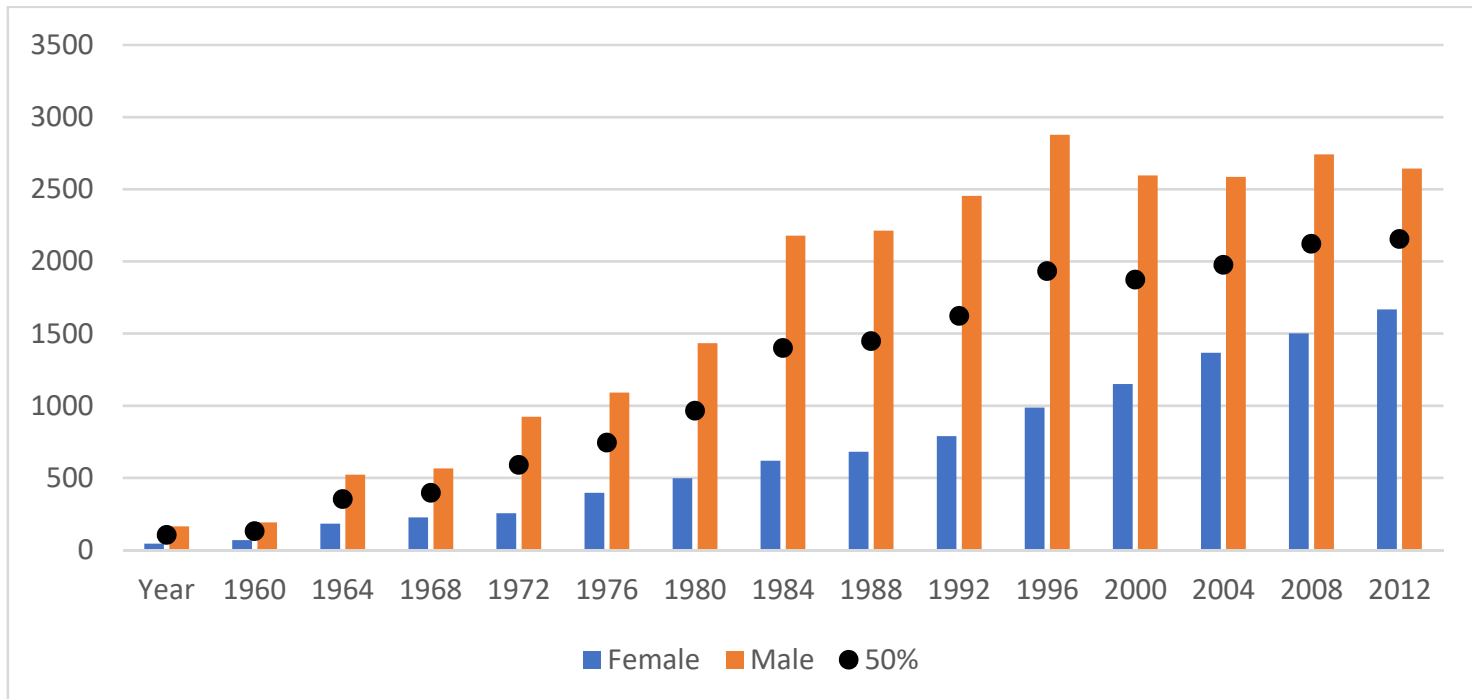

Figure 2. Number of Paralympians by sex by year from 1960 to 2016. The black dot in the graph represents the cut-off of $50 \%$ to show the existing gap in male and female participation.

\subsection{Participation and Achievement in Events Requiring Assistive Products}

In sports requiring assistive products (wheelchair, handcycle, or prosthesis-requiring sports), participation also differs by income level. Table 2 shows the number of events requiring assistive products participated in since 1996 (sum of all years 1996-2016). Highincome countries have significantly higher levels of participation in events requiring assistive products than low- and middle-income countries $(p=0.000)$. Achievement represents the proportion of events participated in where a medal was won. High, uppermiddle, and lower middle-income countries demonstrate significantly higher achievement than low-income countries $(p=0.007)$.

Table 2. Participation and achievement in events requiring assistive products from 1996 to 2016 by income level.

\begin{tabular}{|c|c|c|c|c|c|}
\hline Participation & Low & Low Middle & Upper Middle & High & \\
\hline $\begin{array}{c}\text { Events requiring assistive } \\
\text { products participated in since } \\
1996(\mathrm{n})\end{array}$ & 9 & $103 *$ & $160 *$ & $612 * *$ & \\
\hline $\begin{array}{c}\text { Events participated in where a } \\
\text { medal was won }(\%)\end{array}$ & 0.00 & $22.33 *$ & $27.50 *$ & $46.57^{* *}$ & \\
\hline Achievements ${ }^{2}$ & Low & Low middle & Upper middle & High & Overall medals \\
\hline Wheelchair basketball & 0.00 & 0.00 & 0.00 & $90(100 \%)$ & 90 \\
\hline Wheelchair fencing & 0.00 & $8(3.5 \%)$ & $43(18.9 \%)$ & $176(77.6 \%)$ & 227 \\
\hline Wheelchair tennis & 0.00 & 0.00 & $1(1.0 \%)$ & $93(99.0 \%)$ & 94 \\
\hline Wheelchair rugby & 0.00 & 0.00 & 0.00 & $15(100.0 \%)$ & 15 \\
\hline $\begin{array}{c}\text { Wheelchair athletics } \\
100 \text { m track race (classification } \\
\text { T32-34 and 51-54) }\end{array}$ & 0.00 & $2(1.5 \%)$ & $25(18.8 \%)$ & $106(79.7 \%)$ & 133 \\
\hline
\end{tabular}


Table 2. Cont.

\begin{tabular}{|c|c|c|c|c|c|}
\hline $\begin{array}{l}\text { Long jump with prosthesis } \\
\text { (classification F42-44) }\end{array}$ & 0.00 & 0.00 & $4(7.4 \%)$ & $50(92.6 \%)$ & 54 \\
\hline $\begin{array}{l}\text { Athletics: Running with } \\
\text { prosthesis } 100 \mathrm{~m} \\
\text { Classification T42-44 }\end{array}$ & 0.00 & $1(1.8 \%)$ & $6(11.1 \%)$ & $47(87.0 \%)$ & 54 \\
\hline $\begin{array}{l}\text { Athletics: Running with } \\
\text { prosthesis } 200 \mathrm{~m} \\
\text { Classification T44 }\end{array}$ & 0.00 & 0.00 & $4(13.3 \%)$ & $26(86.7 \%)$ & 30 \\
\hline $\begin{array}{c}\text { Athletics: Running with } \\
\text { prosthesis } 400 \mathrm{~m} \\
\text { Classification T44 }\end{array}$ & 0.00 & 0.00 & $2(11.1 \%)$ & $16(88.9 \%)$ & 18 \\
\hline $\begin{array}{l}\text { Athletics: relay } 4 \times 100 \mathrm{~m} \\
\text { Classification T44-46 }\end{array}$ & 0.00 & 0.00 & $4(26.067 \%)$ & $11(72.4 \%)$ & 15 \\
\hline Hand cycle race & 0 & 0 & $1(1.0 \%)$ & $92(99.0 \%)$ & 93 \\
\hline
\end{tabular}

${ }^{2}$ Number and proportion (\%) of medals won per event participated in by each country. ${ }^{*}$ Indicates a significant difference $(p \leq 0.05)$ from low income countries. ${ }^{* *}$ Indicates a significant difference $(p \leq 0.05)$ from low, low middle, and upper middle-income countries.

Table 2 also provides an overview of achievement for different events requiring the use of assistive products. Since 1996, medals for wheelchair rugby and basketball were won only by high income countries. Wheelchair tennis medals were also unanimously won by high income countries, apart from one silver medal won by an upper-middle income country, Thailand, in 2004. Wheelchair track event medals were also dominated by high income settings. The $100 \mathrm{~m}$ track race was won by a Paralympian from a high-income country in $80 \%$ of races. Hand cycling events commenced at the Paralympics in 2004 for males and 2008 for females. Of the 93 medal winners, three were Paralympians representing a non-high-income setting. Sports that required the use of a lower limb prostheses were won mostly by Paralympians representing high income countries. Across included athletic events since 1996, more male events were held, and more medals awarded. High-income settings accounted for $93 \%$ of medals awarded for long jump, and upper middle-income settings made up the remaining $7 \%$. In the 100, 200, and $400 \mathrm{~m}$ running races, no lowincome country won a medal over the time period. In all considered prosthetic sports, over $90 \%$ of medals were won by high income countries.

\section{Discussion}

This study retrospectively analyzed participation and achievement at the Paralympic Games, considering country income, athlete sex, and use of assistive products. To date, no study described historic trends in participation and achievements of countries from different income levels at the Paralympic Games, including events requiring selected assistive products. The findings from this help to build our understanding of gaps in participation and medal success across the Paralympic Games, and how they relate to income. The results of our study align with the broader literature supporting income level and sex as major determinants of Paralympic participation and achievement.

Our findings indicate that high-income countries send more athletes to the Paralympics compared to low- and middle-income countries. While there has been an increasing participation of low-income countries over the course of the 15 Paralympic Games, many of these countries have only ever sent one athlete to compete. This finding is in line with previous studies, which suggested that participating athletes from less-resourced settings were significantly lower compared to Paralympians from Europe or North America [9]. In addition, our study found that higher participation is linked to achievement and medal success. Bigger team size has been previously linked to higher success [9]; however, as the broader literature supports, other important factors may influence Paralympic achievement, such as inclusive-sport practices and policies, opportunities for 
training, and early access to high quality assistive products [11]. Based on our data, upper middle-income countries such as Argentina and Brazil have registered high participation throughout the 15 Paralympic Games; however, they were less represented in global medal tables compared to countries from the same income level and with similar participation rates (e.g., China). Another important finding from our study is that high-income countries have significantly higher rates of achievement compared to low- and middle- income countries. In addition, the rate of achievement becomes more consistent with the increasing of the income level. Most competing high-income countries won a medal, presenting a more homogenous distribution of success across participating countries compared to countries from low- and middle-income levels. For example, medal tables of low-income countries are dominated by four countries, while the majority of competing countries from this income level never won a medal. Further studies are important to enhance understanding these outlying scenarios, and determinants, in addition to participation, which contribute to achievements and success.

This research, along with the broader literature, establishes females as consistently underrepresented in Paralympic events. Despite political, social, and cultural trends promoting inclusion through which overall participation grew in the Paralympics for both sexes, female Paralympians across the globe continue to face barriers to participation and achievement as elite athletes [5]. With regards to the proportion of female Paralympic participants, little progress has been made over more than a decade [20]. Interestingly, our current research found that the proportionality of female to male participants was similar across countries of different income levels, suggesting barriers to female participation at the Paralympics are experienced globally (including in high-income countries). This finding contrast with literature reports that women from low-and middle- income countries experience more exclusion. As this research has shown, low- and middle- income countries are almost completely absent from participation and achievements in events requiring assistive products, with middle-income countries presenting a very small presence. WHO reports that less than $10 \%$ of people have access to the assistive products they need to live independent participatory lives [12]. Given that many low- and middle-income countries have severely limited national service delivery for assistive technology, it is unsurprising that the necessary high quality assistive products for participation in elite sports are also largely unavailable [12]. Assistive products for day-to-day activities are not suitable for participating in sport, which require different design features [11]. Sports specific assistive products, particularly wheelchairs, prostheses, and handcycles have evolved in technical attributes including materials and design, with sports-specific assistive products now available [11]. Sports-specific assistive products tend to be more expensive than standard assistive products due to the use of advanced materials such as composite material (titanium, carbon fiber, etc.). Paralympians representing high income countries are often provided with sports-specific assistive products via government subsidy schemes or via sponsorship arrangements reducing, the likelihood of affordability posing a barrier to participation. For the Paralympic Games to meet its expressed goal of fairness and inclusion for all persons with disabilities globally, availability and affordability of assistive products for sport must urgently be addressed. Recognized barriers to access to assistive products for everyday life likely also underpin barriers to access to assistive products to participate in sport. In line with the Convention on the Rights of Persons with Disabilities, WHO describes five key areas for system reform to support increased access to assistive technology, including high quality assistive products for sports [21]. These include the establishment of inclusive sport and assistive technology policies, mainstreaming the provision of high quality assistive products across all levels of care, and promoting international cooperation. These measures would help to achieve fairness and realize truly inclusive societies through engagement with sport as a right which promotes access to culture. Both previous studies and the findings from this research highlight gaps and inequalities in participation and achievements at the Paralympics. We expect these findings to stimulate further research on access to assistive technology in the context of the Paralympics and 
beyond, to inform future reforms, to promote fairness, and to increase equality of access to quality assistive technology.

\section{Limitations}

Data were extracted from publicly available sources. The authors acknowledge that data entry errors may have occurred during the data extraction and uploading process into the database. Every effort was made to ensure data accuracy. For example, data extracted were checked by three authors for correctness. Income levels may have changed for some countries over the included years of analysis. While the calculations involving income level were based on the countries' income level by year, for analyses which report all years combined, the income level most commonly achieved by the country (mode) is reported here and used in the analysis, therefore this might present some inaccuracies. Furthermore, we were unable to account for all potential factors which may have impacted the variables of interest in the analysis, therefore it is possible that additional variables may have had an impact on the participation and achievement rates.

Limited events were selected for inclusion in the analysis in this study. Included events were selected as a representative cross section of events that require prostheses, wheelchairs, and hand cycles. Whilst it can be inferred that participation in these events would be mirrored in other events requiring these assistive products, applying this research to other events not included for analysis should be done thoughtfully.

\section{Conclusions}

Influences on Paralympic participation and achievement is a vastly under researched area, with very little exploration of the influence of access to high quality assistive products. Despite the remarkable growth of the Paralympic movement and increased global participation, important gaps remain: our study shows that high-income countries send, on average, more Paralympians than low- and middle-income countries, and demonstrate significantly higher achievement across all events, including in sports requiring assistive products. In addition, our study reports a significant underrepresentation of females compared to males.

For a nuanced understanding of influences on participation and achievement in Paralympic events that require assistive technology, it is important to recognize the inherent inequalities in global access to assistive technology and sex disparity. Without doing so, and without increasing equitable access to assistive technology for all, growth of participation from low-and middle-income countries and achievement in the Paralympics will be unlikely. National reforms and programs to increase access to high-quality assistive products, inclusive policies, partnerships, and international cooperation are urgently needed to tackle the inequitable access to high quality assistive products and disparities in sex representation, participation, and achievements at the Paralympics. Within the framework of the Convention of the Rights of Persons with Disabilities, it is time for global stakeholders to partner together to accelerate equitable provision of high-quality assistive products, accessible training, and sport facilities and create opportunities for persons with disabilities to engage in competitive events and foster inclusion.

Author Contributions: We warrant that this manuscript is original; and its substance has not been previously published in part or in whole. All authors reviewed the manuscript for important intellectual content and provided critical review, verified the underlying data, and contributed to the validation of methods and approaches used for the analysis. Specific authors' contribution is as following: conceptualization, G.O. and C.K.; data curation, L.P. and E.M.S.; formal analysis, L.P. and E.M.S.; investigation, G.O. and L.P.; methodology, G.O., L.P. and E.M.S.; project administration, G.O.; software, E.M.S.; supervision, C.K.; validation, G.O.; writing-original draft, G.O. and L.P.; writing-review and editing, E.M.S. and C.K. All authors have read and agreed to the published version of the manuscript.

Funding: This research received no external funding. 
Institutional Review Board Statement: Not applicable.

Informed Consent Statement: Not applicable.

Data Availability Statement: The data presented in this study are openly available in the International Paralympic Committee website [https:/ /www.paralympic.org/paralympic-games-results] and World Bank [https:/ / datahelpdesk.worldbank.org/knowledgebase/articles/906519-worldbank-country-and-lending-groups] (accessed on 18 June 2021).

Acknowledgments: We wish to thank Clive Ondari (Director, Health Products Policy and Standards, $\mathrm{WHO}$ ) for his technical support to this project, and Krizzia Melo-Maramba (Assistive Technology and Medical Devices Unit, WHO) for administration support.

Conflicts of Interest: The authors declare no conflict of interest.

Disclaimer: The authors alone are responsible for the views expressed in this article and they do not necessarily represent the views, decisions, or policies of the institutions with which they are affiliated.

\section{Appendix A. List of Countries Included in the Research}

\begin{tabular}{ll} 
1. & Afghanistan \\
2. & Albania \\
3. & Algeria \\
4. & Andorra \\
5. & Angola \\
6. & Antigua and Barbuda \\
7. & Argentina \\
8. & Armenia \\
9. & Aruba \\
10. & Australia \\
11. & Austria \\
12. & Azerbaijan \\
13. & Bahamas \\
14. & Bahrain \\
15. & Bangladesh \\
16. & Barbados \\
17. & Belarus \\
18. & Belgium \\
19. & Benin \\
20. & Bermuda \\
21. & Bosnia and Herzegovina \\
22. & Botswana \\
23. & Brazil \\
24. & Brunei Darussalam \\
25. & Bulgaria \\
26. & Burkina Faso \\
27. & Burundi \\
28. & Cambodia \\
29. & Cameroon \\
30. & Canada \\
31. & Cape Verde \\
32. & Central African Republic \\
33. & Chile \\
34. & Chinese Taipei \\
35. & Colombia \\
36. & Comoros \\
37. & Congo \\
38. & Costa Rica \\
39. & Cote D'Ivoire \\
\hline la
\end{tabular}




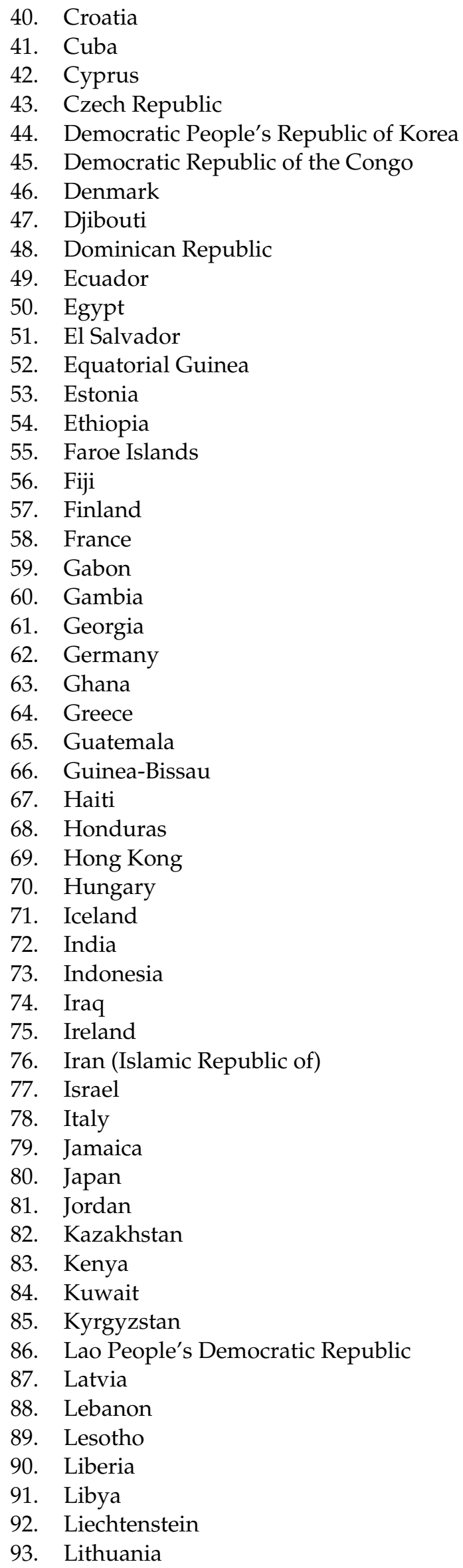




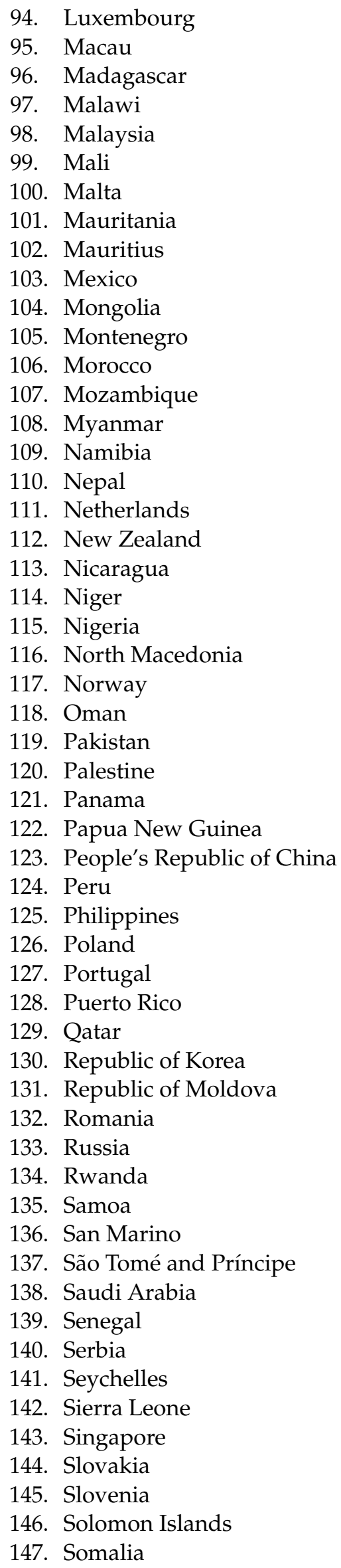




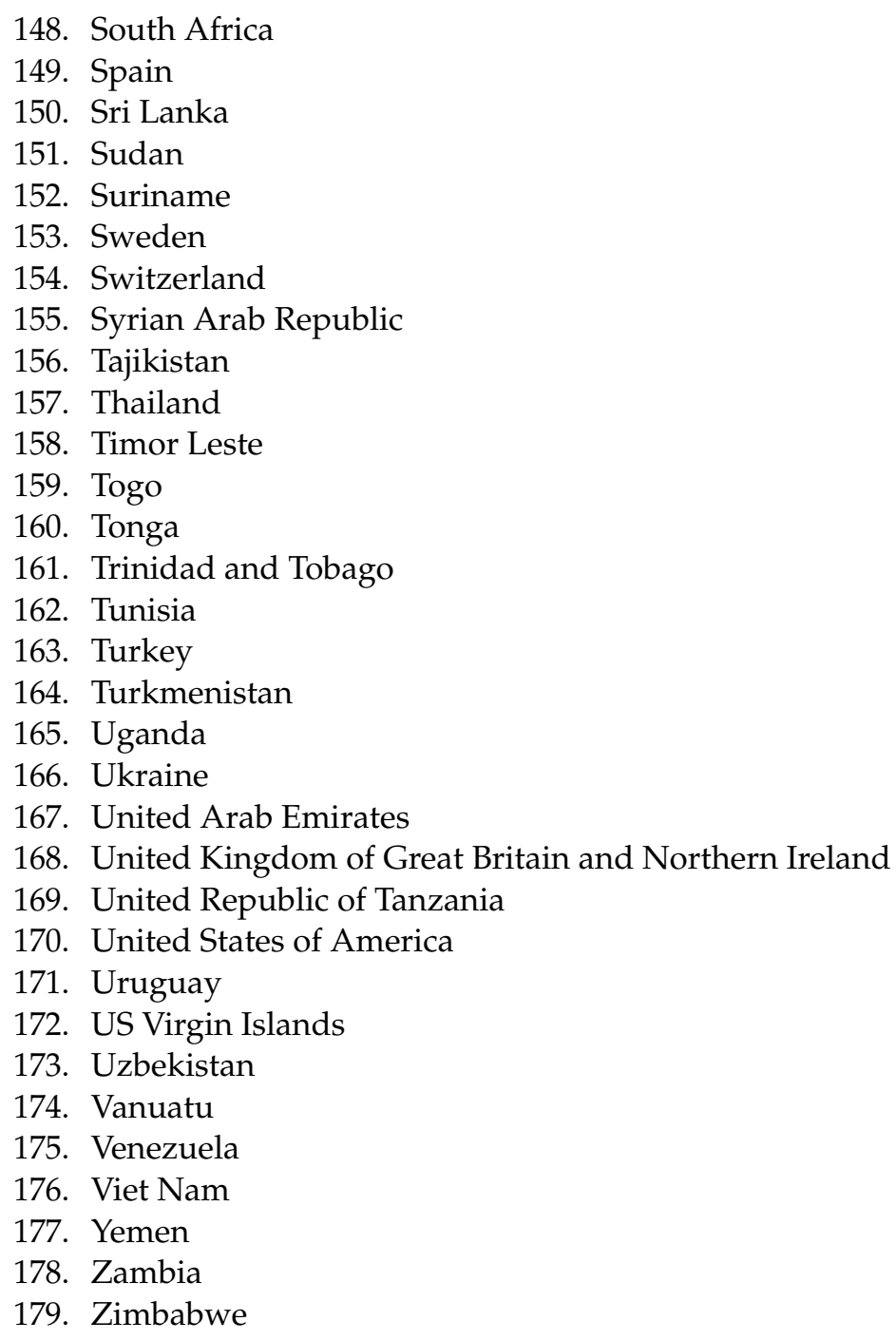

\section{References}

1. United Nations. Convention on the Rights of Persons with Disabilities (CRPD); United Nations: New York, NY, USA, 2021.

2. United Nations Assembly. Convention on the Rights of the Child. Treaty Ser. 1989, 1577, 1-23.

3. United Nations Assembly. Convention on the Elimination of all Forms of Discrimination against Women; United Nations: New York, NY, USA, 1979.

4. Blauwet, C.; Willick, S.E. The Paralympic Movement: Using sports to promote health, disability rights, and social integration for athletes with disabilities. PM \& R the J. Inj. Funct. Rehabil. 2012, 4, 851-856.

5. Women's Sport Foundation. Women in the Olympic and Paralympic Games: An Analysis of Participation, Leadership and Media Coverage; Women's Sport Foundation Research Series; Women's Sport Foundation: New York, NY, USA, 2017.

6. Goh, C.L. To what extent does the Paralympic Games promote the integration of disabled persons into society? Int. Sports Law J. 2020, 20, 36-54. [CrossRef]

7. Swartz, L.; Bantjes, J.; Rall, D.; Ferreira, S.; Blauwet, C.; Derman, W. “A More Equitable Society”: The Politics of Global Fairness in Paralympic Sport. PLoS ONE 2016, 11, e0167481. [CrossRef] [PubMed]

8. Brittain, I. The Impact of Resource Inequality upon Participation and Success at the Summer and Winter Paralympic Games. J. Paralympic Res. Group 2019, 12, 41-67.

9. Mauerberg-deCastro, E.; Campbell, D.; Tavares, C.P. The global reality of the Paralympic Movement: Challenges and opportunities in disability sports. Mot. Rev. De Educ. Física 2016, 22, 111-123. [CrossRef]

10. Dyer, B.; Sewell, P.; Noroozi, S.; Redwood, S.; Broomfield, S.; Callaway, A. Sprint prostheses used at the Paralympics: A proposal for an assessment method to maintain fairness. Prosthet. Orthot. Int. 2012, 36, 306-311. [CrossRef] [PubMed]

11. Burkett, B. Technology in Paralympic sport: Performance enhancement or essential for performance? Br. J. Sports Med. 2010, 44, 215-220. [CrossRef] [PubMed]

12. World Health Organization, Assistive Technology Factsheet; WHO: Geneva, Switzerland, 2020. 
13. MacLachlan, M.; Banes, D.; Bell, D.; Borg, J.; Donnelly, B.; Fembek, M.; Ghosh, R.; Gowran, R.J.; Hannay, E.; Hiscock, D.; et al. Assistive technology policy: A position paper from the first global research, innovation, and education on assistive technology (GREAT) summit. Disabil. Rehabil. Assist. Technol. 2018, 13, 454-466. [CrossRef] [PubMed]

14. Smith, R.; Scherer, M.J.; Cooper, R.; Bell, D.; Hobbs, D.A.; Pettersson, C.; Seymour, N.; Borg, J.; Johnson, M.J.; Lane, J.P.; et al. Assistive technology products: A position paper from the first global research, innovation, and education on assistive technology (GREAT) summit. Disabil. Rehabil. Assist. Technol. 2018, 13, 473-485. [CrossRef] [PubMed]

15. Smith, E.M.; Gowran, R.J.; Mannan, H.; Donnelly, B.; Alvarez, L.; Bell, D.; Contepomi, S.; Wegner, L.E.; Hoogerwerf, E.; Howe, T.; et al. Enabling appropriate personnel skill-mix for progressive realization of equitable access to assistive technology. Disabil. Rehabil. Assist. Technol. 2018, 13, 445-453. [CrossRef] [PubMed]

16. Matter, R.; Harniss, M.; Oderud, T.; Borg, J.; Eide, A.H. Assistive technology in resource-limited environments: A scoping review. Disabil. Rehabil. Assist. Technol. 2017, 12, 105-114. [CrossRef] [PubMed]

17. Baker, D.A.J.S. The "Second Place" problem: Assistive technology in sports and (Re) constructing normal. Sci. Eng. Ethics 2016, 22, 93-110. [CrossRef] [PubMed]

18. Nordic Centre for Rehabilitation Technology (NUH). Provision of Assistive Technology in the Nordic Countries. In Nordic Cooperation on Disability Issues; Nordic Centre for Rehabilitation Technology (NUH): Tampere, Finland, 2007.

19. ECORYS, Mapping on Access to Sport for People with Disabilities: A Report to the European Commission; European Commission: Brussels, Belgium, 2018.

20. Smith, M.M.; Wrynn, A.M. History of gender and gender equality in the Olympics and Paralympics. In Routledge HandBook of Sport, Gender and Sexuality; Routledge: London, UK, 2014; pp. 77-85.

21. World Health Assembly. Item A71/21. Improving Access to Assistive Technology: Report by the Director-General; WHO: Geneva, Switzerland, 2018. 